\title{
FORMAÇÃO DE FUTUROS PROFESSORES DE MATEMÁTICA: UMA EXPERIÊNCIA COM AÇÕES PEDAGÓGICAS NÃO FORMAIS
}

\author{
Training of future mathematics teachers: \\ an experience with non-formal pedagogical actions
}

\author{
Anemari Roesler Luersen Vieira Lopes ${ }^{1}$ • Maria Teresa Ceron \\ Trevisol $^{2}$. Maria Lucinda Corcetti ${ }^{3}$
}

\begin{abstract}
Resumo: Este artigo apresenta parte de uma pesquisa desenvolvida com alunos de um curso de licenciatura em matemática que participam de um programa de filantropia. O principal objetivo deste texto é investigar as possíveis contribuições que o envolvimento de futuros professores em ações pedagógicas não formais pode trazer para a sua formação. Pretende, ainda, verificar quais as percepções que os licenciandos, que participam desse programa, têm sobre a carreira docente, sua inserção no curso de licenciatura em matemática e no programa, e as relações dessa participação com possíveis aprendizagens da docência. De abordagem qualitativa, trata-se de um estudo de caso, cujos dados foram obtidos a partir de um questionário composto por perguntas abertas. As referências diretas aos aspectos considerados positivos em relação a ações desenvolvidas no programa, quando de suas respostas ao questionário, trazem fortes indícios de que o envolvimento dos futuros professores nestas ações contribuiu para a sua formação docente.
\end{abstract}

Palavras-chave: Formação de professores. Docência. Ensino de matemática. Ensino Superior.

\begin{abstract}
This article presents part of a study developed with students on a degree course in Mathematics who took part in a philanthropy program. The main objective of this text is to investigate the possible contributions that the involvement of teachers in non-formal educational actions may bring to their training. It also intends to analyze what are the perceptions that undergraduate students who participate in this program have on the teaching profession, their insertion into the mathematics degree course and in the program and the relations of such participation with possible teaching and learning. With a qualitative approach, it is a case study with data obtained from a questionnaire with open questions. Direct references to the aspects considered positive in relation to the actions undertaken in the program, according to their answers to the questionnaire, bring increasing evidence that the future teachers' involvement contributed to their teacher training.
\end{abstract}

Keywords: Teacher education. Learning of teaching. Mathematics teaching. Higher education.

\footnotetext{
${ }^{1}$ Programa de Pós-Graduação em Educação, Universidade Federal de Santa Maria. Avenida Roraima, 1000, Cidade Universitária. Camobi, Santa Maria, RS, Brasil. 97.105-900. anemari.lopes@gmail.com

${ }^{2}$ Programa de Mestrado em Educação, Universidade do Oeste de Santa Catarina (Unoesc), campus de Joaçaba. Joaçaba, SC, Brasil.

${ }_{3}^{3}$ Área de Ciências Humanas e Sociais (ACHS), Unoesc, Unidade de Capinzal. Capinzal, SC, Brasil.
} 


\section{Introdução}

A preocupação com a formação do professor, em especial do que ensina Matemática, vem nos acompanhando há algum tempo e não tem sido exclusividade nossa. Esse tema faz parte das discussões dos principais eventos da área de Educação e Educação Matemática, constituindo grupos de trabalhos específicos, como nas reuniões da Associação Nacional de Pesquisa e Pós-graduação em Educação (Anped) e do Simpósio Internacional de Pesquisa em Educação Matemática (SIPEM); ou organizados em temas, como no Encontro Nacional de Educação Matemática (ENEM), e subtemas, no Encontro Nacional de Didática e Prática de Ensino (Endipe). Além disso, recentes publicações, seja em periódicos, seja em livros, vêm divulgando resultados de pesquisas voltadas para essa temática.

Encontramos, nesses estudos, diferentes enfoques, perspectivas teóricas e metodológicas sobre a formação do professor de Matemática, cuja diversidade se justifica e se torna importante à medida que compreendemos que a docência é uma profissão complexa, que se constitui em diferentes espaços, e sobre a qual interferem inúmeros fatores.

Nesse vasto contexto, tentando contribuir com os debates, apresentamos os resultados de uma pesquisa que tem o olhar voltado à inserção de futuros professores em um projeto de filantropia: o Programa de Alfabetização Regional (PAR), da Universidade do Oeste de Santa Catarina (Unoesc).

Essa instituição, distribuída em cinco campi, localiza-se na região Oeste do estado, cuja população corresponde a um quinto da estadual. Caracteriza-se como uma universidade regional e comunitária e, como é característica no caso das instituições dessa natureza, ela possui fortes relações com a região de sua abrangência, formada por pequenos municípios.

Entre as questões relativas à educação regional que perpassam pelas reflexões pedagógicas da universidade, uma delas refere-se à formação de professores. Acompanhando uma problemática nacional, os cursos da área de Educação, que historicamente deram os primeiros passos da instituição, começaram a entrar em crise no início dos anos de 1990 em razão da pouca procura.

Além das questões relativas à desvalorização do magistério, que atinge os cursos de licenciatura em geral, aos das instituições não públicas (verificar), agrega-se o problema das questões financeiras. Analisando-se de um ponto de vista "racional", o custo-benefício de um curso de licenciatura é consideravelmente maior do que de outros cursos que, futuramente, podem oferecer oportunidades profissionais com remunerações mais atrativas.

As perspectivas de mudanças nesse quadro, no campus de Joaçaba, iniciaram-se a partir de 2004, com a implantação do Programa de Alfabetização Regional (PAR). Seu objetivo principal, desde então, era promover a melhoria da educação formal e não formal na região, mediante ações com alunos e de assessoria aos professores das redes públicas estaduais e municipais de ensino, na perspectiva da inclusão social e formação da cidadania.

Esse programa de filantropia, que envolve exclusivamente os cursos de licenciatura, oferece bolsa de cinquenta por cento do valor da mensalidade para o acadêmico. Em contrapartida, o licenciando desenvolve ações na comunidade de sua cidade de origem, nas residências das pessoas interessadas, ou, ainda, em núcleos organizados em empresas, espaços comunitários e em escolas públicas conveniadas com a universidade. Para isso, o aluno disponibiliza duas horas semanais, distribuídas entre as ações e os encontros com a coordenação. A inserção 
no programa é voluntária; contudo, até hoje, não houve nenhum caso de aluno de licenciatura que não participasse dele.

Inicialmente, no PAR, realizavam-se ações exclusivamente com adultos não alfabetizados. Todavia, a partir de 2007, passaram a ser desenvolvidos seis projetos principais: Vivências lúdicas em espaços educativos; Assessoria didático-pedagógica; Alfabetização/escolarização de jovens e adultos; Alfabetização cultural; Leitura na escola; Construção de material didático. A partir disso, começaram a se envolver todos os cursos de licenciatura atualmente mantidos na Área das Ciências Humanas e Sociais da Unoesc campus de Joaçaba: História, Letras, Artes, Matemática e Pedagogia. Como os seis projetos do PAR representam um amplo leque de possibilidades de atuação, os licenciandos são orientados a desenvolverem ações ligadas às particularidades do seu respectivo curso.

O encaminhamento inicia-se pela organização individual, ou em pequenos grupos, de um projeto específico vinculado a um dos projetos principais (anteriormente citados); em continuidade, dá-se a aceitação dessas propostas por parte de uma das entidades conveniadas com a Unoesc. Uma prática que vem sendo adotada pelos estudantes é a elaboração do projeto junto com a escola onde serão desenvolvidas as ações, as quais são acompanhadas, periodicamente, pela coordenação do programa; no final do ano, é apresentado o relatório final por escrito, em evento específico para tal.

A reflexão sobre a possibilidade de que a inserção desses acadêmicos no programa, por meio do desenvolvimento de ações pedagógicas, mesmo de âmbito não formal, pudesse representar um momento singular para a formação dos futuros professores, mobilizou a efetivação de uma pesquisa ${ }^{4}$, com o principal objetivo de investigar as possíveis contribuições que o envolvimento de futuros professores de Matemática em ações pedagógicas não formais pode trazer à sua formação. Neste artigo, que traz os principais resultados da pesquisa, nossa intenção específica também é verificar: quais as percepções que os licenciandos, participantes do programa, possuem sobre a educação; a carreira docente; a sua inserção no curso de licenciatura em Matemática, no programa PAR, e as relações dessa participação com prováveis aprendizagens da docência.

Cabe salientar que entendemos como ações pedagógicas não formais aquelas que visam ao ensino e à aprendizagem, mas que se caracterizam por representarem maneiras diferenciadas de trabalhar com a educação, mesmo quando desenvolvidas em unidades escolares. Embora possuindo uma estrutura e organização, elas divergem das formais, sobretudo no que diz respeito às formas de encaminhamento, à não-fixação de tempos e à flexibilidade na adaptação dos conteúdos de aprendizagem para cada sujeito ou grupo (AFONSO, 1992, p. 86).

Diante da impossibilidade de pesquisarmos a atuação de todos os envolvidos no programa, investigamos a formação dos futuros professores de Matemática. Justifica-se tal opção a partir de estudos realizados com professores da região de Joaçaba (LOPES, 2006), que têm indicado que um número significativo de professores de Matemática que atuam na Educação Básica não possui licenciatura específica na disciplina. Além disso, entre aqueles

${ }^{4}$ A coleta de dados teve a colaboração da acadêmica do curso de Matemática Simoni Cristiani Zeni Cora Godoy. 
que a possuem, grande parte aponta lacunas na própria formação inicial, no que se refere, sobretudo, à relação entre teoria e prática. Salienta-se que o curso de Licenciatura em Matemática da Unoesc campus de Joaçaba, campus Aproximado de Capinzal, e o curso da Unoesc campus de São Miguel do Oeste, representam, atualmente, os únicos oferecidos em regime presencial de toda a região Oeste de Santa Catarina. Esses cursos abrangem 118 municípios catarinenses, além de alguns da região Noroeste do Rio Grande do Sul. Tais fatores despertam uma profunda preocupação com o ensino da Matemática, com a formação de professores e com a seriedade a ser atribuída às investigações em Matemática desenvolvidas na perspectiva da educação.

Esta pesquisa, de abordagem qualitativa, caracteriza-se como um estudo de caso (LUDKE; ANDRE, 1986), uma vez que foi investigado o caso específico dos alunos da primeira turma de licenciatura em Matemática da Unoesc campus de Joaçaba, do campus Aproximado de Capinzal, que participam do Programa de Alfabetização Regional.

Os 29 alunos componentes da turma foram convidados a participar; vinte concordaram, dos quais oito do gênero masculino e 12 do feminino. Entre eles, 11 têm idade entre 18 e 23 anos, cinco de 24 a trinta anos e apenas quatro acima de trinta anos. São alunos residentes em oito diferentes municípios da região do Meio-Oeste de Santa Catarina e Noroeste do Rio Grande do Sul. Entre os vinte, apenas seis já tinham alguma experiência como professor. Em relação à formação de nível médio, encontramos $50 \%$ dos pesquisados com formação geral no Ensino Médio, 30\% no magistério e 20\% com outra modalidade de formação.

Os dados foram obtidos a partir do uso de procedimentos organizados com base no respeito aos critérios éticos e sigilo das informações ${ }^{5}$, coletados a partir de um questionário composto por 16 perguntas abertas. Neste artigo discutiremos aquelas que se mostraram mais relevantes para a elucidação do objetivo proposto. Como forma de garantir a não-identificação dos participantes, no decorrer do texto, eles serão nomeados com a palavra Acadêmico, seguida da numeração de 1 a 20, que lhes foi atribuída de forma aleatória. As respostas foram organizadas por semelhança de argumentos e, quando muito dispersas, apresentadas em quadros em ordem decrescente de frequência.

Inicialmente, apresentamos uma breve fundamentação teórica que nos ampara em relação à formação de professores. Posteriormente, trazemos os dados organizados em três grupos. O primeiro - Sobre ser professor de Matemática - apresenta as percepções que os sujeitos têm sobre o professor, a educação, a profissão docente e a sua inserção no curso de licenciatura em Matemática. O segundo - Sobre atuar no Programa de Alfabetização Regional - traz a compreensão deles acerca da participação no programa. O terceiro - Sobre o Programa de Alfabetização Regional e a Aprendizagem da Docência - apresenta os significados atribuídos, pelos acadêmicos participantes da experiência do PAR, na aprendizagem de ser docente. Por fim, traçamos algumas considerações a respeito dos dados obtidos.

\footnotetext{
${ }^{5}$ Os participantes, após terem sido esclarecidos sobre os propósitos da pesquisa, leram e assinaram o Termo de Consentimento Livre e Esclarecido, segundo orientações do Comitê de Ética em Pesquisa. 
Formação de futuros professores de Matemática: ...

\section{Breves apontamentos teóricos}

As pesquisas sobre formação de professores desenvolvidas nos últimos tempos vêm conduzindo a sua compreensão como um processo contínuo, que se inicia antes dos cursos de licenciatura e se prolonga por toda a vida.

Nesse sentido, ela não acontece em intervalos independentes ou espaços determinados, mas constitui um movimento que, conforme Fiorentini e Castro (2003, p. 124), “[...] acontece nos múltiplos espaços e momentos da vida de cada um, envolvendo aspectos pessoais, familiares, institucionais e socioculturais."

A partir dessa consideração, também podemos entender que a aprendizagem da docência pode acontecer em diferentes contextos. Mizukami (2006, p. 214) lembra que "conhecimentos teóricos diversos assim como aqueles que têm como fonte a experiência pessoal e profissional são objetos de aprendizagem constantes."

Assim, conhecimentos e saberes relativos à profissão docente não são constituídos somente nos espaços formais de formação, como o curso de licenciatura. Tampouco podem ser considerados como acabados, nem imutáveis, uma vez que são apropriados e reconfigurados ao longo da vida do professor, nas relações que ele estabelece, inclusive, no desenvolvimento de atividades pedagógicas não formais.

Partindo da ideia de que a docência é uma atividade complexa, Mizukami (2006, p. 215) destaca dois pontos centrais para a formação de professores.

Considera-se como pontos centrais em qualquer processo de formação da docência - inicial ou continuada - dois aspectos importantes para se preparar bons professores que possam propiciar condições que seus alunos aprendam: a organização das situações de ensino que possibilitem aprendizagens para alunos diferentes e de trajetórias pessoais e culturais diversas e a construção de conhecimentos sobre o ensino dos diferentes componentes curriculares.

Tomamos esses dois aspectos, apontados pela autora, como particularmente importantes no encaminhamento desta pesquisa, à medida que também os compreendemos como reveladores da aprendizagem da docência.

Em relação à organização das situações de ensino, enfatizamos a contribuição de Moura (2001, p. 144) que, entendendo que o professor é o sujeito responsável pela ação pedagógica e apoiando-se no pressuposto da didática de que é possível a organização de processos de ensino mais eficientes que outros, afirma que “[...] ter a profissão de professor é organizar situações cujos resultados são as modificações do sujeito a quem intencionalmente visamos modificar." Para esse autor, a organização do ensino é um elemento fundamental no processo de ensino-aprendizagem, à medida que viabiliza a apreensão de conhecimentos tanto para o professor, ao desenvolvê-la, quanto para o aluno.

Acerca dos processos de formação, a organização do ensino pode configurar-se como base orientadora das ações pedagógicas, uma vez que, por meio dela, pode-se adquirir uma visão mais ampla do trabalho, o que lhe confere maior segurança, especialmente na interação com os alunos. Organizar o ensino implica escolher conteúdos, instrumentos, estratégias; e as 
opções assumidas, materializadas em propostas educativas, determinam o processo de ensino adotado pelo professor e, consequentemente, de aprendizagem do aluno.

A oportunidade de um professor colocar-se em uma situação que lhe imponha a necessidade de organização de ensino pode auxiliá-lo a tomar consciência do sistema educacional, compreendendo o papel do ensino e do educador diante das condições educacionais postas (MOURA, 2001).

A organização do ensino configura-se como uma ação intencional do professor, o que implica a responsabilidade, por ele assumida, sobre o ato de ensinar. Como ação docente, precisa, também, passar por um processo de aprendizagem, de apropriação de conhecimentos, que serão relevantes à medida que possam contribuir para a compreensão e melhor desenvolvimento da docência.

Em relação aos saberes e aos conhecimentos da profissão docente, vários autores têm trazido suas contribuições, embora com diversidades conceituais e metodológicas, fazendo uso de diferentes tipologias e classificações. Entre eles, destacam-se: Shulman (1986), que foi um dos precursores desses estudos; Tardif (2002); Fiorentini, Souza Júnior e Melo (1998); Gauthier et al. (1998).

Ao se buscar a contribuição de Gauthier et al. (1998), observa-se que os pesquisadores fazem referência a um reservatório de conhecimentos: disciplinares, curriculares, das ciências da Educação, da tradição pedagógica, experienciais e da ação pedagógica. Este último da ação pedagógica - forma o que denominam de repertório de conhecimentos, que são característicos da função de professor e distinguem essa profissão das outras, sendo constituídos na prática docente e determinados mediante o estudo do trabalho do professor.

$\mathrm{Na}$ perspectiva desses autores, pode-se dizer que o conhecimento disciplinar (ou científico) é o conjunto dos conhecimentos produzidos por pesquisadores e cientistas de cada disciplina científica, e correspondem às diferentes áreas do conhecimento, disponíveis sob a forma de disciplinas. O conhecimento curricular é aquele que o professor deve ter sobre o programa da disciplina ensinada na escola, que é o resultado da organização e da seleção dos conhecimentos produzidos pela ciência. O conhecimento da tradição pedagógica é formado por conhecimentos originados a partir da estruturação da escola como uma entidade de ensino coletivo. É o saber dar aulas a partir de representações prévias que o professor tem antes mesmo de sua formação pedagógica. $\mathrm{O}$ conhecimento experiencial é adquirido por meio das próprias experiências. $\mathrm{O}$ conhecimento das ciências da Educação constitui o conjunto dos conhecimentos profissionais adquiridos durante a formação ou, mesmo, no transcorrer do trabalho, e que pode não estar especificamente ligado ao conteúdo da disciplina que leciona. O conhecimento da ação pedagógica (também denominado de pedagógico ou docente) é o conhecimento experiencial que se torna público e é testado por meio de pesquisas realizadas em sala de aula.

Os conhecimentos e saberes da profissão docente vão sendo constituídos ao longo da história de vida do professor; aqueles relacionados à ação pedagógica são compreendidos, produzidos ou ressignificados na realização do trabalho pedagógico. Expresso de outra forma, "[...] os saberes da atividade profissional do professor são situados, uma vez que ganham sentido quando em relação com a prática e, portanto, não são ensinados, mas aprendidos mediante um processo reflexivo sobre o trabalho" (FIORENTINI; CASTRO, 2003, p. 152).

Daí entendermos a importância de o futuro professor, durante o curso de formação inicial, inserir-se em situações que lhe permitam o desenvolvimento de ações pedagógicas 
Formação de futuros professores de Matemática: ...

desencadeadas como resultado da organização do ensino, oportunizando a apropriação de conhecimentos.

\section{Futuros professores de Matemática e o Programa de Alfabetização Regional}

\section{Sobre ser professor de Matemática}

De início, trazemos algumas questões respondidas pelos acadêmicos referentes às suas percepções sobre educação, profissão docente e sua inserção no curso de Licenciatura em Matemática.

Ao serem questionados sobre o que consideram importante aprender no curso de licenciatura para ser um bom professor, os argumentos recaíram sobre dois aspectos: conhecimento de conteúdo (55\%) e diversificação das práticas pedagógicas (45\%).

O conhecimento do conteúdo, ou disciplinar, nas palavras de Gauthier et al. (1998), pode ser entendido como o conjunto dos conhecimentos produzidos por pesquisadores e cientistas de cada disciplina científica. Assim, correspondem às diferentes áreas do conhecimento e encontram-se disponíveis à sociedade sob a forma de disciplinas. Logo, é um conhecimento primordial para o futuro professor, uma vez que, para ensinar, é preciso saber o conteúdo, e isso envolve os mais diferentes aspectos da Matemática: conhecimento da estrutura da disciplina; dos conceitos fundamentais e do método; da história e da construção dos conceitos; entre outros.

A preocupação dos estudantes com a diversificação das práticas pedagógicas está relacionada ao conhecimento da ação pedagógica (também denominado de pedagógico ou docente) que, de acordo com Gauthier et al. (1998), é o conhecimento experiencial que se torna público, testado por meio de pesquisas realizadas em sala de aula. É por meio dessas pesquisas que as experiências dos professores podem ser comparadas e avaliadas, a fim de se estabelecerem regras de ação que podem ser aprendidas por outros professores.

Tradicionalmente, os cursos de Matemática, assim como outros da Área das Ciências Exatas, caracterizam-se por uma forte preocupação com o conhecimento do conteúdo, relegando o conhecimento relativo à ação pedagógica a outro plano, seguindo um modelo de racionalidade técnica que separa teoria e prática. $\mathrm{Na}$ verdade, grande parte das críticas direcionadas aos cursos de formação inicial, como o de Matemática, direciona-se a questionar sua capacidade de formar bons professores, sobretudo quanto à dicotomia teoria (conhecimento matemático) e prática (conhecimentos pedagógicos).

Assim, o fato de que parte considerável dos alunos de um curso de Licenciatura em Matemática aponta como importante a aprendizagem relacionada à prática docente sustenta-se como um aspecto positivo. Essa importância, por eles atribuída, pode ser constatada no comentário de um dos estudantes sobre o que considera relevante aprender para a carreira docente.

\footnotetext{
"Conhecer a realidade de nossos alunos, criar estratégias de ensinoaprendizagem, entender a evolução da educação e seus processos, ser mediador do conhecimento". (Acadêmico 1)
} 
Esse registro contempla a expectativa do Programa de Alfabetização Regional (PAR) em relação à integração do acadêmico no meio social da região e no escolar.

Outra questão buscou saber o que os acadêmicos consideram significativo para um docente, salientando as características que atribuíam a um "bom professor". As respostas relacionam-se a oito aspectos, agrupados por semelhança, na Tabela 1.

Pergunta: Em sua opinião, quais são as características de um bom professor?

Tabela 1. Características de um bom professor para os pesquisados

\begin{tabular}{lc}
\hline \multicolumn{1}{c}{ Argumentos utilizados pelos acadêmicos } & Total \\
\hline Bom mediador do conhecimento/aprendizagem & 7 \\
Conhecedor das realidades escolares & 3 \\
Dedicado à sua profissão & 3 \\
Pesquisador & 3 \\
Conhecedor dos conteúdos & 2 \\
Ético & 1 \\
Inovador & 1 \\
Total & $\mathbf{2 0}$ \\
\hline
\end{tabular}

Fonte: Dados da pesquisa

As respostas mais frequentes relacionam-se à ação do professor na aprendizagem do aluno (35\%), o que demonstra que os acadêmicos concebem como bom professor aquele que é capaz de fazer com que o aluno aprenda. Além disso, três acadêmicos fazem referência ao conhecimento das realidades escolares, e três apontam a dedicação à profissão, valorizando, desse modo, a importância de o professor estar inteirado do contexto em que a escola está inserida e assumir a docência como profissão. Destacamos dois comentários, a seguir, sobre como deve ser esse professor.

"Saber respeitar a individualidade de cada aluno, entender a organização e a dinâmica de uma escola [...]". (Acadêmico 5)

"Ele deve ser preocupado com o desempenho no que faz, com a aprendizagem do aluno [...]”. (Acadêmico 2)

Ser pesquisador é também uma característica apontada como importante por três acadêmicos, dos quais realçamos uma justificativa.

"Ser pesquisador, estar se atualizando sempre para aprofundar seu conhecimento". (Acadêmico 9)

Salientamos que a conotação de pesquisador, apresentada pelos acadêmicos, difere do conceito de "professor pesquisador" como aquele que investiga a sua prática profissional de modo a melhorar o seu ensino e as instituições educativas (ZEICHNER, 1993, 1998), que foi merecedora de destaque no Brasil, sobretudo nos anos de 1990. Embora o projeto do 
Formação de futuros professores de Matemática: ...

ponto de vista teórico preveja essa perspectiva e haja esforços por parte da coordenação para que isso aconteça, as respostas não demonstram que esteja presente nas ações dos acadêmicos.

Ainda em relação às características de um bom professor, somente dois estudantes (10\%) apontam para o ponto "ser conhecedor do conteúdo". Lembramos que, ao serem questionados sobre quais conhecimentos, adquiridos no curso de licenciatura, foram importantes, o conhecimento do conteúdo foi apontado por mais da metade dos participantes (55\%), como descrito anteriormente. Esse fato pode estar relacionado à crença, muito difundida entre os professores, de que o curso universitário oferece os conhecimentos teóricos, e a experiência, os conhecimentos docentes, que, muitas vezes, são considerados como os mais importantes para o exercício da docência. Isso significa que os alunos acreditam que o sujeito aprende a ser professor quando inicia sua carreira docente, e a experiência cotidiana sobrepõe-se sobre qualquer conhecimento no ofício de professor. Algumas dessas ideias preconcebidas contribuem para uma visão simplista e empírica do trabalho pedagógico, como: para ser bom professor, é suficiente ter talento; bom senso, seguir a intuição, ter experiência, ter cultura. Tais ideias, que partem do senso comum, podem impedir a manifestação de saberes profissionais específicos, pois não relacionam a competência à posse de um saber próprio ao ensino (GAUTHIER et al., 1998).

Também foram apontadas outras duas características: ser ético e inovador, ambas citadas por um participante do grupo, o que não significa que tenha sido a mesma pessoa.

Outra pergunta buscou saber os motivos que levaram os acadêmicos a escolher a docência em Matemática. Suas respostas, agrupadas por semelhança, encontram-se na Tabela 2.

Pergunta: Por que escolheu o curso de Matemática?

Tabela 2. A escolha do curso de Matemática

\begin{tabular}{lc}
\hline \multicolumn{1}{c}{ Argumentos utilizados pelos acadêmicos } & Total \\
\hline Identificação com a disciplina & 14 \\
Objetividade da área & 2 \\
Importância dos conteúdos na escola & 1 \\
Aquisição de conhecimentos novos & 2 \\
Ser um professor diferente & 1 \\
Total & $\mathbf{2 0}$ \\
\hline
\end{tabular}

Fonte: Dados da pesquisa

A maior parte dos acadêmicos $(70 \%)$ justificou sua resposta fazendo referência à afinidade com a disciplina, como podemos perceber nestes comentários:

"Simplesmente por gostar de Matemática". (Acadêmico 15)

"Porque me identifico com esta disciplina". (Acadêmico 4)

"Porque me identifico com a disciplina e, quando era estudante da educação básica, considerava a maneira das aulas um tanto forçada”. (Acadêmico 5) 
Além disso, dois deles argumentaram o fato de que a Matemática é uma disciplina exata e objetiva, o que lhes agrada; um refere-se à importância da Matemática na matriz curricular da Educação Básica. Somados aos demais, podemos dizer que, para $85 \%$ dos acadêmicos, a opção pelo curso de licenciatura em Matemática está relacionada ao conhecimento matemático, e não, necessariamente, à docência.

Acrescentemos que a Matemática escolar ainda apresenta muitos mitos, em especial, o da dificuldade de aprendizagem, atribuindo-lhe a conotação de que nem todos podem aprendêla. Dessa forma, subentende-se que, se é uma disciplina que poucos entendem, aqueles que possuem esse conhecimento detêm o atributo de poder ensiná-la. Contudo, a pergunta que fica é: entender Matemática é o suficiente para ensinar Matemática?

O depoimento da Acadêmica 5 nos traz, contudo, outra perspectiva: a de superar aquilo que ficou faltando em sua formação escolar, indicando que a maneira como lhe era ensinada Matemática era "um tanto forçada", e isso justificaria sua intenção em seguir a docência em Matemática.

Dois acadêmicos referem-se a adquirir novos conhecimentos, sem justificar o que isso significaria; outro explicita claramente sua intenção em ser professor de Matemática em uma perspectiva diferente, como consta no depoimento:

"Para ser um professor diferente e fazer a diferença em relação ao ensino de Matemática”. (Acadêmico 19)

Os futuros professores foram questionados sobre sua visão em relação à docência. A maior parte deles referiu-se à profissão como importante e gratificante. No entanto, destacam a pouca valorização.

\footnotetext{
"Acho uma profissão importante, pois é a base do conhecimento de todos os indivíduos, mas é pouco valorizada". (Acadêmico 6)

"Pouco valorizada pela sociedade por ser uma profissão que contribui para a preparação do indivíduo para a sociedade". (Acadêmico 1)
}

Os depoimentos indicam que esses estudantes entram no curso e vão iniciar a carreira trazendo a ideia de que a docência é uma profissão não valorizada. Estudos, como os de Ludke e Boing (2004), apontam para o fato de que a profissão docente exibe sinais evidentes de precarização com a perda de prestígio, poder aquisitivo, condições de vida, respeito e satisfação. Essa questão, que emerge da complexa situação pela qual passa o magistério na atualidade, está relacionada ao profissional em exercício, mas influencia a visão dos futuros professores que, diferente de outrora, não entram na carreira com uma perspectiva utópica de que é uma profissão sem problemas.

\section{Sobre atuar no Programa de Alfabetização Regional}

Nesta subseção, abordamos questões que possuem como objetivo observar qual a compreensão que os sujeitos têm acerca de sua participação no Programa de Alfabetização 
Formação de futuros professores de Matemática: ...

Regional. Esclarecemos que eles se encontram no quarto semestre do curso de licenciatura em Matemática; com exceção de um, todos estão vinculados ao PAR, desde o início da graduação.

Ressalta-se que, durante o primeiro semestre, os alunos apenas conhecem o programa e participam de cursos de formação e dos seminários de integração. A partir do segundo semestre, organizam um projeto - individual ou coletivo - pelo qual se tornarão responsáveis, podendo ser desenvolvido em espaços diferenciados: escolas, empresas, associações comunitárias ou em residências (no caso de alfabetização/alfabetização Matemática de adultos). O projeto deve ser aprovado pela coordenação do programa e entidade e/ou pessoa envolvida.

Os projetos desenvolvidos pelos sujeitos pesquisados constam na Tabela 3.

Tabela 3. Ações desenvolvidas no Programa de Alfabetização Regional

\begin{tabular}{lc}
\hline \multicolumn{1}{c}{ Projeto } & Total \\
\hline Alfabetização Matemática de Adultos & 7 \\
Assessoria Didático-pedagógica & 5 \\
Laboratórios de Ensino de Matemática & 4 \\
Vivências Lúdicas em Espaços Educativos & 3 \\
Alfabetização em Informática & 1 \\
Total & $\mathbf{2 0}$ \\
\hline
\end{tabular}

Fonte: Dados da pesquisa

Os acadêmicos do curso de Matemática, em sua grande maioria, envolvem-se em trabalhos ligados à sua área específica, o que exige uma organização peculiar para isso, considerada como positiva por eles, como podemos verificar nos depoimentos:

"Acho que é muito importante porque abre caminhos para novos conhecimentos mostrando que cada indivíduo tem o dever de prestar serviço à comunidade”. (Acadêmico 1)

"Muito importante, pois além de facilitar o ingresso na faculdade com o auxílio da bolsa, as ações desenvolvidas nos auxiliam no aprendizado, na função de professor". (Acadêmico 11)

A oportunidade de o futuro professor inserir-se em um contexto de aprendizagem da docência ainda na formação inicial, como enfatiza Lopes (2009), pode tornar-se um diferencial importante em sua formação.

Com exceção dos projetos de Alfabetização Matemática de Adultos, que são desenvolvidos em instituições comunitárias e residências, os demais estão inseridos em instituições de ensino, auxiliando os professores, pesquisando e confeccionando materiais alternativos. A prioridade das ações é o atendimento a alunos com dificuldades de aprendizagem em Matemática.

Também questionamos sobre a principal contribuição do PAR aos estudantes envolvidos; as respostas, agrupadas por similaridade, encontram-se na Tabela 4. 
Lopes, A. R. L. V.; Trevisol, M. T. C.; Corcetti, M. L.

Pergunta: Qual a principal contribuição que o Programa de Alfabetização Regional está trazendo para você?

Tabela 4. Contribuições do programa para os acadêmicos

\begin{tabular}{lc}
\hline \multicolumn{1}{c}{ Argumentos utilizados pelos acadêmicos } & Total \\
\hline Crescimento humano e profissional & 8 \\
Aprendizagem para a profissão & 8 \\
Contribuição ao aprendizado da comunidade & 4 \\
Total & $\mathbf{2 0}$ \\
\hline
\end{tabular}

Fonte: Dados da pesquisa

Dos futuros professores, oito fazem menção ao crescimento humano e profissional no sentido de se sentirem gratificados pelos resultados das ações desenvolvidas -, que iria além do auxílio financeiro da bolsa de estudos.

"Com certeza, além do auxílio financeiro, o Programa de Alfabetização Regional nos possibilita um crescimento bastante amplo como seres humanos e futuros profissionais". (Acadêmico 4)

Relacionado, de certa forma, a essa justificativa, quatro estudantes fazem menção à contribuição do PAR para o aprendizado da comunidade, como podemos observar no depoimento a seguir.

"Não é apenas financeira, é também ver a realização e a transformação no rosto das crianças e adultos que ajudamos através do Programa de Alfabetização Regional". (Acadêmico 18)

Como ressaltado, o programa caracteriza-se por estabelecer fortes vínculos com a comunidade, por atender grupos de pequenas cidades que, normalmente, não recebem muita atenção de outras entidades; assim, a presença da universidade é muito bem recebida.

As inserções dos estudantes, em qualquer um dos espaços, embora aconteçam através de ações pedagógicas não formais, à medida que não constituem aulas da forma como tradicionalmente se concebe, exigem uma organização pedagógica. Vejamos três opiniões, entre os oito que fazem referência à importância do PAR para adquirir conhecimentos com vistas à profissão docente.

"Ampliação do conhecimento e desenvolvimento de novas técnicas de ensino". (Acadêmico 7)

"A necessidade de fazer pesquisas para elaborar os projetos e planejar as atividades faz com que a gente aprenda". (Acadêmico 15)

Os comentários apresentados trazem fortes indícios da relevância da organização do ensino, ao fazerem referência a "fazer pesquisa" e "planejar as atividades". Moura (2001) 
destaca que a organização do ensino viabiliza a apropriação de conhecimentos que permitem converter a atividade de ensino, desenvolvida pelo professor, em atividade de aprendizagem da docência.

Questionamos sobre as dificuldades que eles encontram para realizarem os trabalhos vinculados ao programa. As respostas estão compiladas na Tabela 5.

Pergunta: Qual sua principal dificuldade em desenvolver as ações do Programa de Alfabetização Regional?

Tabela 5. Dificuldades em desenvolver as ações relacionadas ao Programa de Alfabetização Regional

\begin{tabular}{lc}
\hline \multicolumn{1}{c}{ Argumentos utilizados pelos acadêmicos } & Total \\
\hline Horários compatíveis & 8 \\
Receptividade das escolas & 4 \\
Falta de orientação & 4 \\
Não tem dificuldades & 2 \\
Não responderam & 2 \\
Total & $\mathbf{2 0}$ \\
\hline
\end{tabular}

Fonte: Dados da pesquisa

A principal dificuldade apontada está relacionada à compatibilidade de horários, uma vez que, assim como na maioria das instituições não públicas, a maior parte dos acadêmicos, além de estudante, possui outra profissão e, por isso, sobram-lhe poucos horários.

As ações propostas pelos acadêmicos às escolas pretendem trabalhar com as instituições, de maneira voluntária, e, em contrapartida, o acadêmico tem a oportunidade de se familiarizar com a prática e a organização escolar, aspectos fundamentais à sua formação. A aceitação por parte da escola, na pessoa dos gestores, normalmente é muito boa e vista como uma oportunidade de contribuição. Contudo, quando o trabalho é diretamente com a sala de aula, o fato de expor suas ações pedagógicas faz com que muitos não aceitem a presença de um estudante, futuro professor. Tal fato é apontado por quatro estudantes como a principal dificuldade no desenvolvimento das ações.

A falta de orientações específicas de como agir diante dos alunos com os quais desenvolvem as ações foi mencionada por quatro estudantes.

"O fato de como fazer com que o aluno com dificuldade aprenda o conteúdo já passado em sala de aula, em aula extraclasse". (Acadêmico 10)

As dificuldades relacionadas ao procedimento nas primeiras ações docentes concretizam um momento que se configura como uma inversão de papéis, em que o aluno passa a ser professor. Esse momento não é tranquilo e "[...] envolve tensões e conflitos entre o que se sabe e o que se idealiza e aquilo que efetivamente pode ser realizado na prática" (FIORENTINI; CASTRO, 2003, p. 122). 
A orientação para os acadêmicos em relação às ações realizadas no projeto é fundamental para o alcance dos resultados esperados. Entretanto, sendo o PAR um programa que envolve todas as licenciaturas da universidade, com uma única coordenadora, as orientações acontecem, mas nem sempre da forma e no tempo em que seriam necessárias. Caberia à instituição buscar encaminhamentos para solucionar essa questão.

\section{Sobre o Programa de Alfabetização Regional e a aprendizagem da docência}

Contemplamos, a seguir, uma questão elaborada com o intuito de verificar, especificamente, se os estudantes percebem possíveis relações entre as ações que desenvolvem no PAR e a sua formação docente, embora aspectos a esse respeito já tenham sido percebidos em respostas às perguntas dos itens anteriores.

Ao serem questionados se achavam que as ações desenvolvidas ajudavam a aprender a ser professor, todos responderam afirmativamente. As justificativas encontram-se na Tabela 6.

Pergunta: As ações desenvolvidas no PAR contribuem para a sua formação como professor?

Tabela 6. Contribuição do PAR para a formação docente

\begin{tabular}{lc}
\hline \multicolumn{1}{c}{ Argumentos utilizados pelos acadêmicos } & Total \\
\hline Preparação do acadêmico para a prática docente & 12 \\
Aprendizagem de novos métodos de ensino & 5 \\
Conhecimento do ambiente escolar & 2 \\
Incentivo à pesquisa & 1 \\
Total & $\mathbf{2 0}$ \\
\hline
\end{tabular}

Fonte: Dados da pesquisa

Grande parte das respostas (60\%) está relacionada à preparação para a prática docente, pautada, sobretudo, no "como agir" com os alunos e com a oportunidade de conhecer o ambiente escolar (10\%), como é possível observar no depoimento que segue:

"Muitas vezes, as pessoas nos fazem perguntas que ainda não sabemos responder; então, não sabemos como agir e temos que ir à busca das respostas. Com o PAR, já vamos tendo aos poucos uma noção da sala de aula”. (Acadêmico 18)

Esse resultado demonstra como o maior receio dos futuros professores quanto ao exercício da profissão não está relacionado ao conhecimento disciplinar da Matemática, mas à ação docente, de maneira particular.

Assinalamos novamente que, em respostas anteriores, o conhecimento disciplinar foi apontado por $55 \%$ dos estudantes como o mais importante a ser adquirido no curso de licenciatura. Contudo, para a ação docente, a preocupação volta-se ao como agir diante dos alunos, 
como se posicionar como professor, o que nos leva à constatação de que parte desses acadêmicos considera aprender Matemática mais fácil do que aprender a ser professor. Vejamos o comentário:

"Quando desenvolvemos o projeto do PAR vamos adquirindo experiência, pois saber o conteúdo é fácil, mas fazer com que aquele aluno que tem dificuldades aprenda é outra coisa". (Acadêmico 9)

Os acadêmicos também citaram a contribuição do PAR para a aprendizagem relacionada às metodologias de ensino $(25 \%)$, sem descartar as possíveis dificuldades que isso pode representar, como podemos evidenciar no depoimento a seguir.

"Porque quando você desenvolve um projeto como este, necessita de dedicação, de força de vontade, organização, etc. O que não é fácil, mas são características essenciais a um professor. E aí vai aprendendo novas formas de ensinar". (Acadêmico 4)

Os futuros profissionais citaram, ainda, o incentivo à pesquisa como uma contribuição importante para o processo de aprendizagem do professor. Essa menção relaciona-se, especialmente, à preocupação demonstrada quanto ao fato de o professor precisar se atualizar constantemente.

"O fato de termos que pesquisar sempre para podermos planejar as atividades leva a gente a aprender mais. O professor não pode parar no tempo". (Acadêmico 11)

Esses relatos nos indicam que, na percepção dos sujeitos desta pesquisa, a inserção no PAR contempla alguns aspectos significativos à formação docente, à medida que oportuniza a inserção em situações de ensino. Isso nos reporta a Moura (2001, p. 147), para quem, na prática docente:

[...] o professor vai compreendendo cada vez mais que, no ato de ensinar está a organização de conhecimentos que deverão propiciar a apreensão de saberes que tornarão os sujeitos mais aptos para viverem socialmente, o que significa que deverão participar conscientemente de uma sociedade cada vez mais justa e humana.

\section{Considerações finais}

A intenção deste artigo foi trazer resultados de uma pesquisa que investigou as possíveis contribuições que o envolvimento de futuros professores de Matemática em ações pedagógicas não formais pode trazer à sua formação. $\mathrm{O}$ estudo visou, especificamente, verificar quais as percepções que os licenciandos, que participam do programa, têm sobre: o professor, 
a carreira docente, a sua inserção no curso de Licenciatura em Matemática e no programa, e as relações dessa participação com possíveis aprendizagens da docência.

Em relação às suas percepções sobre ser professor de Matemática, os dados mostraram que os acadêmicos consideram, como fundamental, aprender, no curso de licenciatura, conhecimentos relativos ao conteúdo, embora também apontem para a importância dos conhecimentos sobre prática docente.

Como características de um bom professor, destacam aquelas relacionadas à ação do professor quanto à aprendizagem do aluno: bom mediador, conhecedor da realidade dos alunos, dedicado à profissão, pesquisador, conhecedor de conteúdos, ético e inovador.

Sobre a opção pelo curso de Licenciatura em Matemática, a maior parte dos acadêmicos apresentou, como justificativa, a sua afinidade com a disciplina, apontando que tal opção está relacionada ao conhecimento matemático, e não, necessariamente, à docência. Quanto à profissão, eles a consideram importante e gratificante, e demonstram ter uma visão realista de seus problemas.

Quanto ao Programa de Alfabetização Regional, por meio de sua atuação que se concentra em diferentes projetos, os acadêmicos destacam a importância da bolsa recebida, mas fazem também menção ao crescimento humano e profissional oportunizado pelo contato com as comunidades, além da aprendizagem para a profissão. Destacam, além disso, a importância de possibilitar o desenvolvimento de ações pedagógicas ainda na formação inicial, mas enfatizam dificuldades no desenvolvimento dessas ações: disponibilidade de horários, aceitação na escola, ou falta de orientações no que se refere aos problemas enfrentados no desencadeamento das ações.

Especificamente sobre a relação entre as ações desenvolvidas e a aprendizagem da docência, mencionam a preparação para a prática docente e a aprendizagem de novos métodos de ensino, além de oportunizar o conhecimento do ambiente escolar. Seus depoimentos mostram que o maior receio no que diz respeito às primeiras ações docentes não está vinculado ao conhecimento disciplinar da Matemática, mas à ação docente, uma vez que se colocar na posição de professor representa um desafio. Para parte considerável deles, aprender Matemática é mais fácil do que aprender a ser professor. Afinal, estamos nos referindo a um processo que não está finalizado ao término do curso de graduação.

Segundo o que afirmam alguns autores já citados, como Shulman (1986); Tardif (2002); Fiorentini, Souza Júnior e Melo (1998); Gauthier et al. (1998), aprendemos a ser professor, ressignificando, constantemente, nossos conhecimentos disciplinares, curriculares, das ciências da Educação, da tradição pedagógica, experienciais (adquiridos por meio das próprias experiências) e da ação pedagógica (conhecimento experiencial), que são característicos da função de professor e distinguem essa profissão das outras, sendo constituídos na prática docente e determinados mediante o estudo do trabalho do professor.

Os conhecimentos e saberes da profissão docente são constituídos ao longo da história de vida do professor; aqueles relacionados à ação pedagógica são compreendidos, produzidos ou ressignificados na realização do trabalho pedagógico. Expresso de outra forma, “[...] os saberes da atividade profissional do professor são situados, uma vez que ganham sentido quando em relação com a prática e, portanto, não são ensinados, mas aprendidos mediante um processo reflexivo sobre o trabalho" (FIORENTINI; CASTRO, 2003, p. 152). 
Formação de futuros professores de Matemática: ...

Sobre as referências diretas aos aspectos considerados positivos das ações de docência desenvolvidas no programa - quando de suas respostas ao questionário -, os alunos trazem fortes indícios de que o envolvimento nessas ações contribuiu para a formação docente. Seus relatos indicam que a inserção no PAR contempla alguns aspectos essenciais da formação dos futuros professores, sobretudo no que se refere: à oportunidade de se colocar na "posição" de professor em diferentes espaços; a desenvolver metodologias de ensino específicas de Matemática; a ter uma visão realista da profissão de professor.

Apesar dos aspectos positivos, há de se voltar a atenção para os problemas apontados pelos estudantes, em especial, àqueles relativos à falta de orientações que os mesmos sentem durante o desenvolvimento das ações. Tais indicações evidenciam a necessidade de criação de um espaço coletivo maior do que o existente atualmente para a reflexão e a análise das ações desencadeadas. Embora os acadêmicos tenham os encontros de orientação com a coordenação e os seminários de socialização, ambos não se mostram suficientes para que os futuros professores interajam com seus pares, exponham suas dificuldades, reflitam sobre suas ações. Essa reflexão deve constituir um espaço coletivo, não se limitando, conforme Sacristán (1995), a deduzir as práticas, mas levando a uma reflexão que propicie uma reorganização pela mobilização dos conhecimentos, conferindo às ações novas qualidades. Esse encaminhamento poderia ampliar as perspectivas da constituição do PAR como um significativo espaço de aprendizagem da docência e de discussões acerca das lacunas presentes nos cursos de licenciatura, que ainda não dão conta de formar um profissional preparado para os desafios atuais do cotidiano educacional.

\section{Referências}

AFONSO, A. J. Sociologia da educação não-escolar: reactualizar um objecto ou construir uma nova problemática. In: ESTEVES, A. J.; STOER, S. (Org.). A sociologia na escola: professores, educação e desenvolvimento. Porto: Afrontamento, 1992. p. 81-96.

FIORENTINI, D.; CASTRO, F. C. Tornando-se professor de matemática: o caso de Allan em prática de ensino e estágio supervisionado. In: FIORENTINI, D. (Org.). Formação de professores de matemática: explorando novos caminhos com outros olhares. Campinas: Mercado de Letras, 2003. p. 121-156.

FIORENTINI, D.; SOUZA JÚNIOR, A. J. de; MELO, G. F. A. Saberes docentes: um desafio para acadêmicos e práticos. In: GERALDI, C. M. C. et al. (Org.). Cartografia do trabalho docente: professor(a)-pesquisador(a). Campinas: Mercado de Letras, 1998. p. 307335 .

GAUTHIER, C. et al. Por uma teoria da pedagogia: pesquisa contemporânea sobre o saber docente. Ijuí: Ed. da Unijuí, 1998.

LOPES, A. R. L. V. Aprendizagem da docência em matemática: o Clube de Matemática como espaço de formação inicial de professores. Passo Fundo: Ed. da UPF, 2009. 
Lopes, A. R. L. V.; Trevisol, M. T. C.; Corcetti, M. L.

LOPES, A. R. L. V. A prática pedagógica e a metodologia do ensino da matemática na formação do professor do Ensino Fundamental na $9^{a}$ Gerei. Joaçaba: Universidade do Oeste de Santa Catarina, 2006. (Relatório de pesquisa). (Mimeografado).

LUDKE, M.; ANDRÉ, M. E. D. A. Pesquisa qualitativa em educação: abordagens qualitativas. São Paulo: EPU, 1986.

LUDKE, M.; BOING, L. A. Caminhos da profissão e da profissionalidade docentes. Educação \& Sociedade, Campinas, v. 25, n. 89, p. 1159-1180, set./dez. 2004.

MIZUKAMI, M. G. N. Aprendizagem da docência: conhecimento específico, contextos e práticas pedagógicas. In: NACARATO, A. M.; FIORENTINI, D. (Org.). A formação do professor que ensina matemática: perspectiva e pesquisas. Belo Horizonte: Autêntica, 2006. p. 213-231.

MOURA, M. O. de. A atividade de ensino como ação formadora. In: CASTRO, A. D.; CARVAlHO, A. M. P. de (Org.). Ensinar a ensinar. São Paulo: Pioneira, 2001. p. 143-162.

SACRISTÁN, J. G. Consciência e ação sobre a prática como libertação profissional dos professores. In: NÓVOA, A. Profissão professor. Portugal: Porto Editora, 1995. p. 63-92.

SHULMAN, L. Those who understand: the knowledge growths in teaching. Educational Researcher, Washington, v. 1,5, n. 2, p. 4-14, feb. 1986.

TARDIF, M. Saberes docentes e formação profissional. Petrópolis: Vozes, 2002.

ZEICHNER, K. A formação reflexiva de professores: idéias e práticas. Lisboa: Educa, 1993.

. Para além da divisão entre professor-pesquisador e pesquisador acadêmico. In: GERALDI, C. M.; FIORENTINI, D.; PEREIRA, E. M. (Org.). Cartografia do trabalho docente: professor(a)-pesquisador(a). Campinas: Mercado de Letras, 1998. p. 207-236.

Artigo recebido em 28/07/2011. Aceito em 15/05/2012. 